\title{
Stereotactic Body Radiotherapy Based on 99mTc-GSA SPECT Image-guided Inverse Planning for Hepatocellular Carcinoma
}

\author{
YUDAI KAI ${ }^{1 *}$, RYO TOYA ${ }^{2 *}$, TETSUO SAITO ${ }^{2}$, TOMOHIKO MATSUYAMA ${ }^{2}$, YOSHIYUKI FUKUGAWA ${ }^{2}$, \\ SHINYA SHIRAISHI ${ }^{3}$, YOSHINOBU SHIMOHIGASHI ${ }^{1}$ and NATSUO OYA ${ }^{2}$ \\ ${ }^{1}$ Department of Radiological Technology, Kumamoto University Hospital, Kumamoto, Japan; \\ ${ }^{2}$ Department of Radiation Oncology, Faculty of Life Sciences, Kumamoto University, Kumamoto, Japan; \\ ${ }^{3}$ Department of Diagnostic Radiology, Faculty of Life Sciences, Kumamoto University, Kumamoto, Japan
}

\begin{abstract}
Background/Aim: A recent planning study suggested that ${ }^{99 m} T c$-labelled diethylene triamine pentaacetate-galactosyl human serum albumin $\left.{ }^{99 m} T c-G S A\right)$ single-photon emission computed tomography (SPECT) image-guided inverse planning (IGIP) shows dosimetric superiority to conventional planning in sparing liver function. Here, we report the first clinical translation of ${ }^{99 m}$ Tc-GSA SPECT IGIP for stereotactic body radiotherapy (SBRT) in a patient with hepatocellular carcinoma (HCC). Case Report: A 60-year-old male developed obstructive jaundice caused by recurrent HCC in segment 1 after hepatic resection. He underwent repeated radiotherapy $(R T)$ consisting of $45 \mathrm{~Gy}$ in 15 fractions 8 years ago and $30 \mathrm{~Gy}$ in 5 fractions 2 years ago. We performed SBRT consisting of 40 Gy in 8 fractions using ${ }^{99 m} T c-G S A$ SPECT-IGIP. We confirmed the dosimetric superiority of functional IGIP to conventional planning. He achieved complete response as assessed using the target volume. The patient has remained alive without recurrence for 18 months. He did not experience radiationinduced liver disease. Conclusion: Recurrent HCC was successfully and safely salvaged via re-irradiation with SBRT using ${ }^{99 m} T c-$ GSA SPECT-IGIP.
\end{abstract}

Hepatocellular carcinoma (HCC) has a high recurrence rate, which is reported to reach $70 \%$ after hepatic resection (1).

This article is freely accessible online.

*These Authors contributed equally to this work.

Correspondence to: Ryo Toya, Department of Radiation Oncology, Faculty of Life Sciences, Kumamoto University, 1-1-1 Honjo, Chuo-ku, Kumamoto 860-8556, Japan. Tel: +81 963735522, Fax: +81963735522, e-mail: ryo108@kumamoto-u.ac.jp

Key Words: Hepatocellular carcinoma, volumetric modulated arc radiotherapy, stereotactic body radiation therapy, re-irradiation, dose-function histogram, single-photon emission computed tomography, radiation-induced liver disease.
Transarterial chemoembolisation (TACE), radiofrequency ablation (RFA) and/or radiotherapy (RT) are repeated to treat recurrent HCC (2-6). These treatment modalities lead to regional damage of the liver function; therefore, the distribution of liver function in patients with HCC is frequently heterogeneous (7). Recently, intensity-modulated radiotherapy (IMRT) based on the inverse planning technique using a dose-volume histogram (DVH) has been initiated into RT for HCC (8). Some groups have suggested that IMRT provides a better target dose conformity with a lower surrounding normal organ dose compared to the 3dimensional (3D) conformal RT in the planning study (8). However, heterogeneity of liver function is not reflected in RT planning because DVH calculation is performed based on computed tomography (CT) morphological images (7).

${ }^{99} \mathrm{~m}$ Tc-labelled diethylene triamine pentaacetate-galactosyl human serum albumin ( $\left.{ }^{99 \mathrm{~m}} \mathrm{Tc}-\mathrm{GSA}\right)$, which specifically binds to the asialoglycoprotein receptor of the liver, is used to evaluate liver function (9). The combined use of ${ }^{99 \mathrm{~m}} \mathrm{Tc}-\mathrm{GSA}$ and single-photon emission computed tomography (SPECT) yields 3D information regarding the distribution of liver function (7). Our recent planning study suggested that ${ }^{99 \mathrm{~m}} \mathrm{Tc}-$ GSA SPECT image-guided inverse planning (IGIP) shows dosimetric superiority to conventional planning in sparing liver function (10). In this case report, we discuss the first clinical translation of ${ }^{99} \mathrm{~m}$ Tc-GSA SPECT-IGIP for stereotactic body radiotherapy (SBRT) in a patient with HCC.

\section{Case Report}

Clinical findings. A 60-year-old man was diagnosed with hepatitis B virus-associated HCC 17 years ago. He underwent hepatic resection of the right posterior section and segment 816 years ago and the left lateral section 4 years ago. He also underwent repeated TACE and RFA for recurrent intrahepatic lesions. For the lesion that relapsed after TACE in segment 1 , he received repeated RT with 45 Gy in 15 fractions 8 years ago and 30 Gy in 5 fractions 2 
years ago (Figure 1). He developed obstructive jaundice because of recurrence of the lesion after RT (Figure 2). An endoscopic retrograde biliary drainage tube was inserted, and the patient had a Child-Pugh score of 6 points. We offered re-irradiation as a treatment option in addition to observation. After obtaining fully informed consent, we performed SBRT according to his wishes.

$R T$ treatment planning. Figure 3 presents the fused planning CT and SPECT/CT image, which was created using Velocity AI (version 3.0.2; Varian Medical Systems, Palo Alto, CA, USA) as described elsewhere (7). The functional liver structure (FLS) for optimisation was decided using a threshold in SPECT at $55 \%$ of the maximum pixel value, which creates a gap in the FLS around the target volume (10). The planning CT images with FLS were transferred to the RT treatment planning system (Monaco version 3.3; Elekta Oncology Systems, Crawley, UK). The structures of the target volume and organs at risk (OARs) were delineated on the planning CT images. A clinical target volume (CTV) margin of $3 \mathrm{~mm}$ was added to the gross tumour volume (GTV). Planning target volume (PTV) margins of $5 \mathrm{~mm}$ for the superiorinferior direction, $4 \mathrm{~mm}$ for the left-right direction and 2 $\mathrm{mm}$ for the anterior-posterior direction were added to the CTV to cover for the internal motion of the target volume and setup errors. Internal motion of the target volume was estimated on the basis of pre-treatment CBCT (11). A functional image-guided SBRT plan (plan F) was generated for treating the patient with photon energy of $6 \mathrm{MV}$ using single arc volumetric modulated arc therapy. A total RT dose of 40 Gy was prescribed to the PTV in 8 fractions. Plan F was optimised to reduce FLS volume receiving $>15$ Gy. A linear accelerator (Synergy; Elekta Oncology Systems) equipped with a 5-mm multi-leaf collimator was used for the treatment. We evaluated liver function in relation to the irradiation dose based on the dose-function histogram (DFH) (7). DFH parameters were calculated for 5-50 Gy as follows:

$\mathrm{Fx}=$ (sum of the counts within the liver volume receiving a dose of $>x \mathrm{~Gy} / \mathrm{sum}$ of the counts within the whole liver volume $) \times 100(7)$.

Treatment plan comparison. In addition to plan F, we created another RT plan that was optimised without FLS (conventional SBRT plan: plan C) to evaluate the dosimetric benefit of plan F. Figure 4 presents the dose distributions of plans $\mathrm{F}$ and $\mathrm{C}$. The low-to-medium dose to the FLS was reduced in plan $\mathrm{F}$ compared to that in plan C. Figure 5 presents the DVH of the non-cancerous liver parenchyma (liver - GTV) and DFH of the liver for plans F and C, and Table I shows their parameters. Although the DVH parameters of the PTV, spinal cord, oesophagus and duodenum were similar in both treatment plans, $\mathrm{F}_{10}$ and $\mathrm{F}_{15}$ of the liver were smaller in plan F compared to plan C.

Patient outcome. After SBRT, the target volume completely disappeared, and the treatment response was considered a complete response (Figure 2). The patient survived without recurrence of the target volume for 18 months. During this period, his Child-Pugh score remained at 6 points, and he did not experience radiation-induced liver disease (RILD).

\section{Discussion}

Functional image-guided RT has been clinically introduced for treating non-small cell lung cancer $(12,13)$; however, it is rarely used in patients with HCC. This paper reports the first clinical translation of $99 \mathrm{~m}$ Tc-GSA SPECT-IGIP for HCC. In this case, inverse planning, based on SPECT image, provided dosimetric superiority to conventional planning in sparing liver function while maintaining the DVH parameters of the PTV and OARs as previously reported in our planning study (10). Some groups have investigated the introduction of functional images of ${ }^{99 \mathrm{~m}} \mathrm{Tc}$-sulphur colloid SPECT, which reflects the Kupffer cell distribution, into treatment planning and assessment of functional liver damage after RT $(14,15)$. Meanwhile, the main feature of ${ }^{99} \mathrm{~m}$ Tc-GSA, which binds the asialoglycoprotein receptor in hepatocytes, is that it enables the direct evaluation of liver function (16).

Re-irradiation for recurrent HCC is extremely challenging. Huang et al. have retrospectively evaluated patients who underwent re-irradiation for recurrent HCC. Of the 36 patients who received two courses of RT, $13(36 \%)$ experienced RILD within 3 months, and 9 (25\%) died of RILD (17). Sophisticated RT techniques are feasible for $\mathrm{HCC}$, especially in cases of re-irradiation. Although our patient previously underwent radiotherapy twice, his recurrent HCC was successfully and safely salvaged via reirradiation with SBRT using ${ }^{99 \mathrm{~m}} \mathrm{Tc}-\mathrm{GSA}$ SPECT-IGIP. Our technique may facilitate the expanded use of RT in patients with HCC, classically considered to have a relatively high risk of RILD.

In summary, we have reported the first clinical translation of SBRT based on ${ }^{99 m}$ Tc-GSA SPECT-IGIP for HCC. We confirmed the dosimetric superiority of functional IGIP to conventional planning in a real clinical setting. Recurrent HCC was successfully and safely salvaged via re-irradiation with SBRT using ${ }^{99 \mathrm{~m}} \mathrm{Tc}-\mathrm{GSA}$ SPECT-IGIP. Our technique may facilitate the expanded use of RT in HCC patients with a relatively high risk of RILD.

\section{Conflicts of Interest}

The Authors declare no conflicts of interest. 

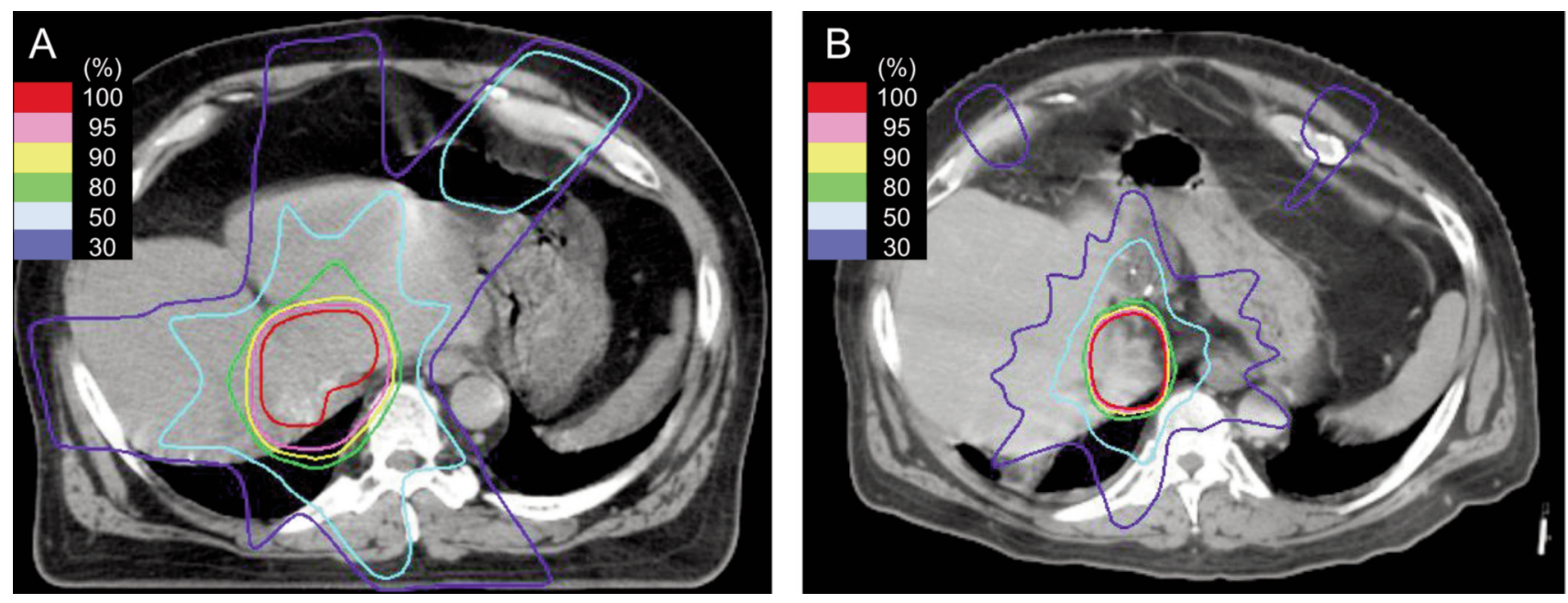

Figure 1. Dose distributions of previous radiotherapy consisting of (A) 45 Gy in 15 fractions and (B) 30 Gy in 5 fractions. Coloured areas illustrate the relative doses to the prescribed doses.
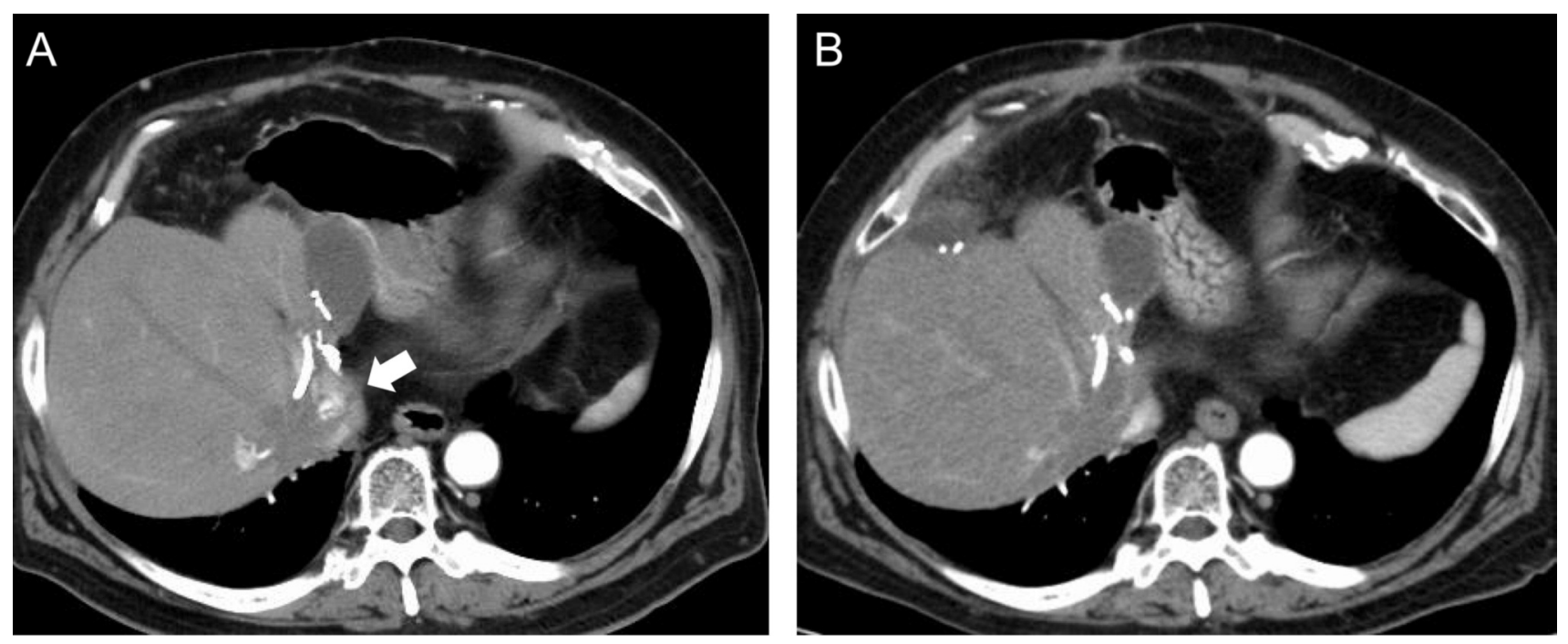

Figure 2. Contrast-enhanced computed tomography. (A) Pre-treatment contrast-enhanced computed tomography $(C T)$ and (B) post-treatment contrast-enhanced CT images obtained 14 months after the completion of stereotactic body radiotherapy (SBRT) consisting of 40 Gy in 8 fractions. The target volume (arrow) completely disappeared after SBRT.
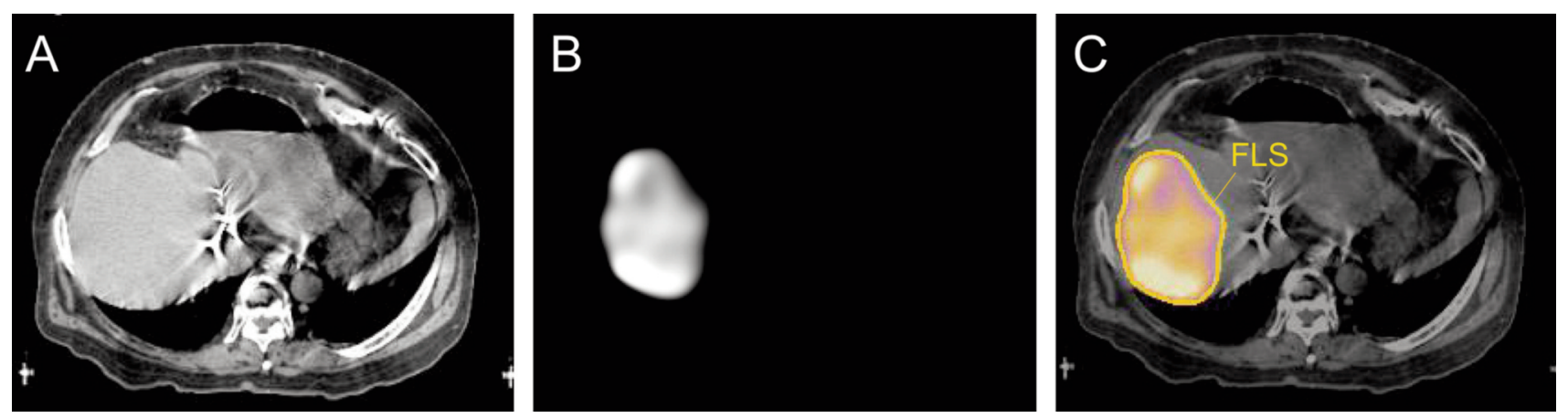

Figure 3. Images for radiotherapy planning. (A) Planning computed tomography (CT), (B) single-photon emission computed tomography (SPECT) and $(C)$ fused planning CT and SPECT image (planning SPECT/CT). The functional liver structure $(F L S)$ is rendered in orange. 

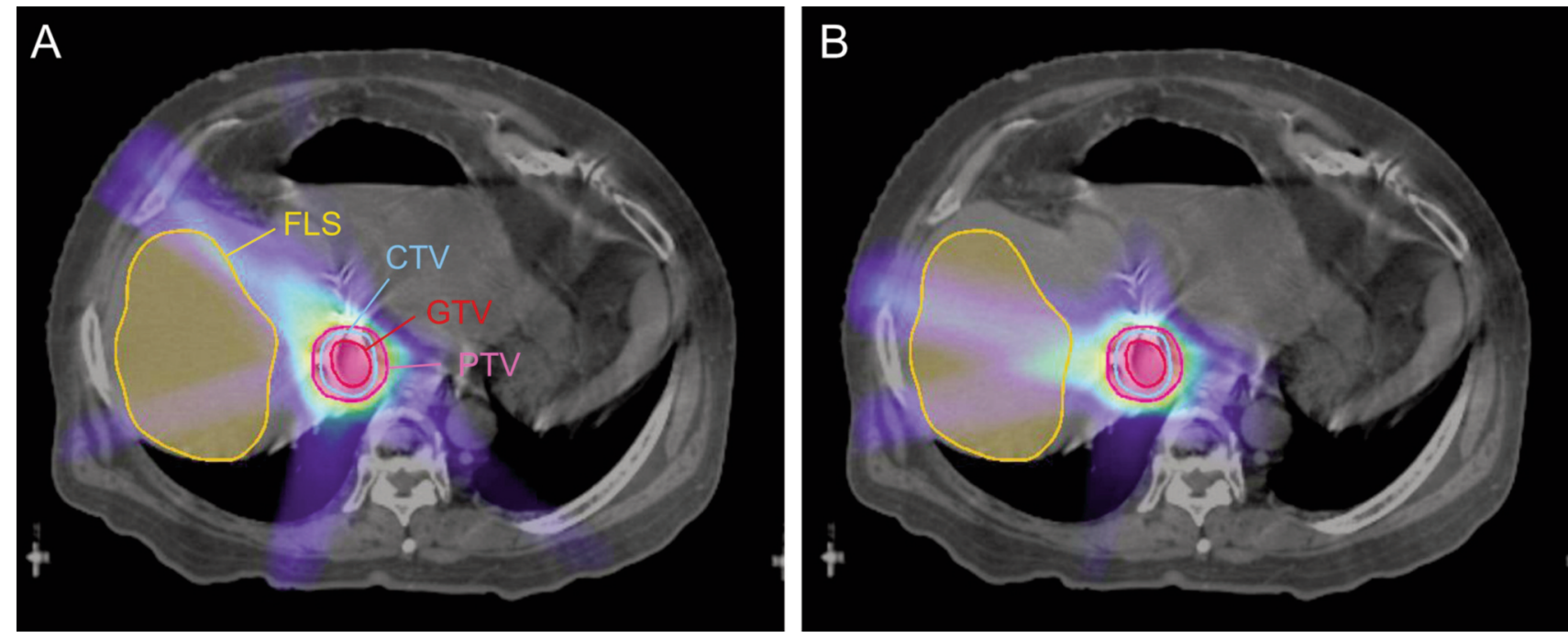

Figure 4. Dose distributions of plans $F(A)$ and plan $C(B)$. The functional liver structure, gross tumour volume, clinical target volume and planning target volume are rendered in orange, red, blue and pink, respectively. FLS: Functional liver structure; GTV: gross tumour volume; CTV: clinical target volume; PTV: planning target volume.

A
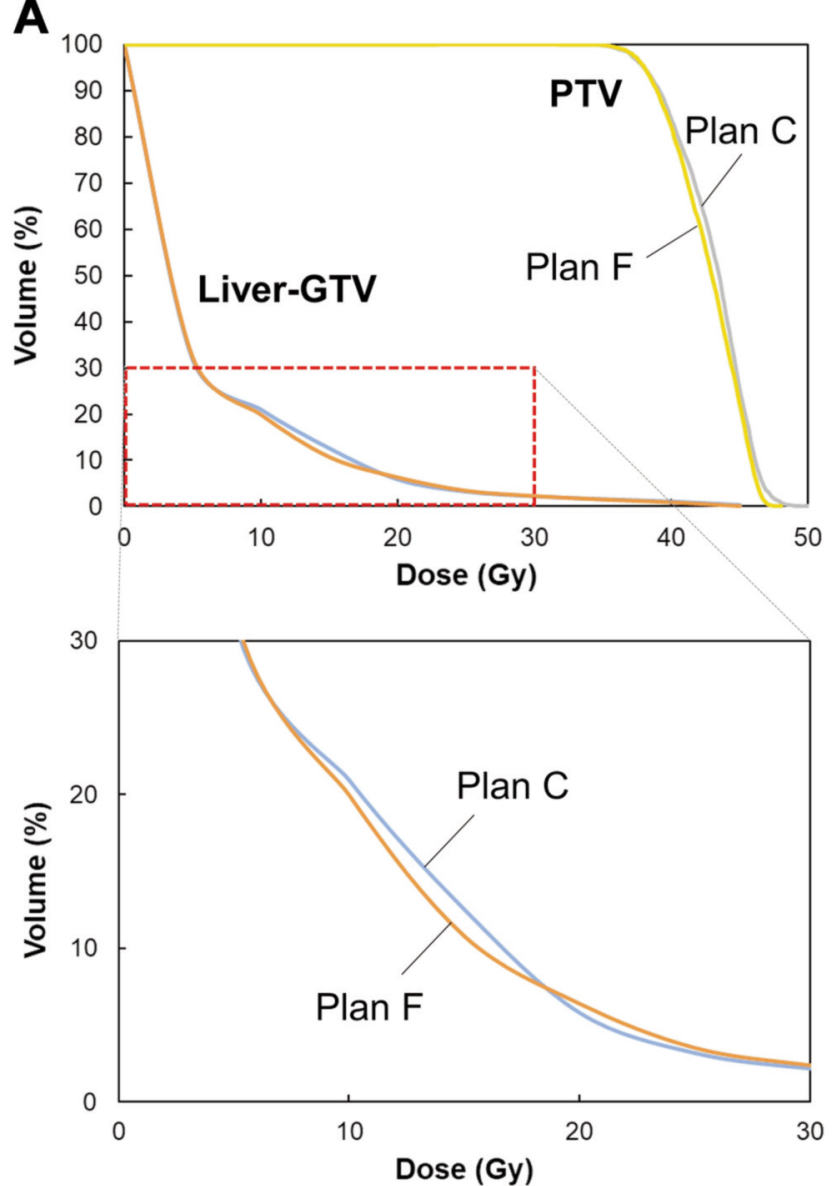

B
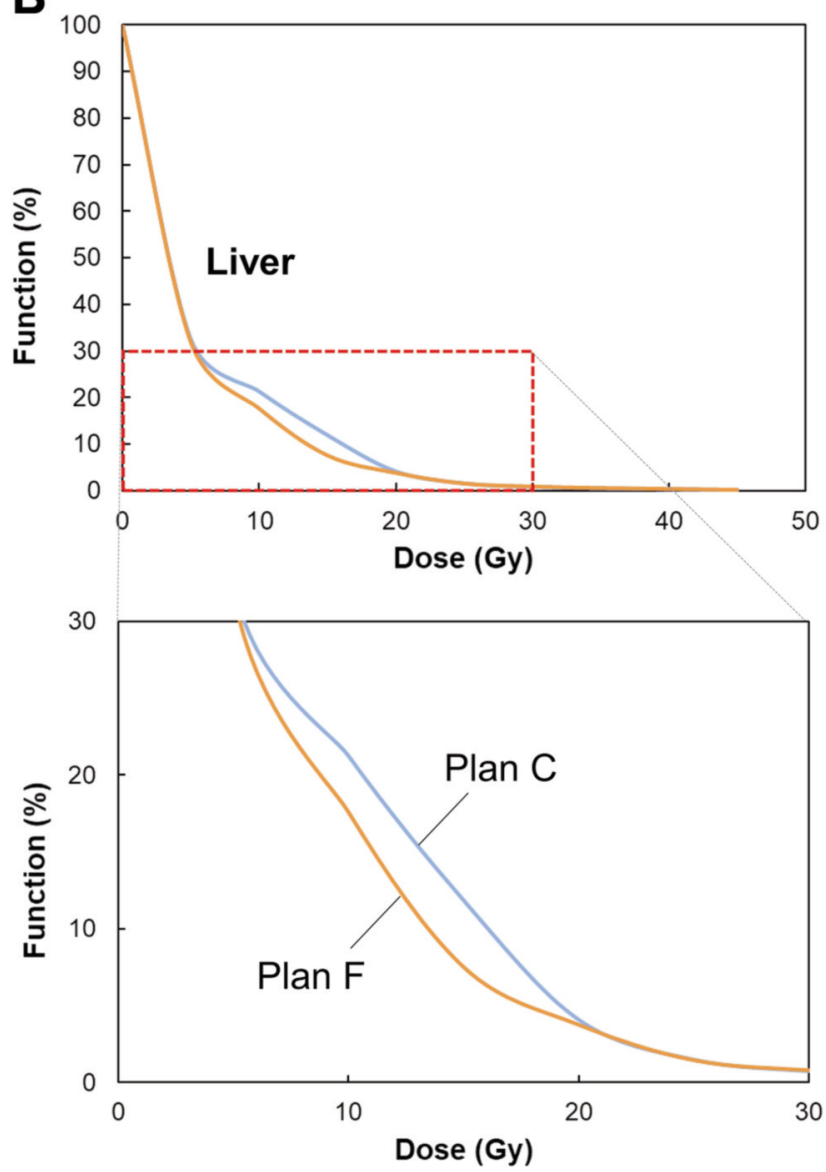

Figure 5. (A) Dose-volume histogram of the non-cancerous liver parenchyma (liver - GTV) and (B) dose-function histogram of the liver. GTV: Gross tumour volume; PTV: Planning target volume. 
Table I. Dose parameters of plans $F$ and $C$.

\begin{tabular}{|c|c|c|c|}
\hline & Plan F & Plan C & Plan F - Plan C \\
\hline \multicolumn{4}{|l|}{ DVH parameter } \\
\hline \multicolumn{4}{|l|}{ PTV } \\
\hline $\mathrm{D}_{95}(\mathrm{~Gy})$ & 38.0 & 38.0 & 0.0 \\
\hline $\mathrm{D}_{98}(\mathrm{~Gy})$ & 37.1 & 37.0 & 0.1 \\
\hline $\mathrm{CI}_{100 \%}$ & 0.81 & 0.82 & -0.01 \\
\hline $\mathrm{CI}_{98 \%}$ & 0.85 & 0.87 & -0.02 \\
\hline $\mathrm{CI}_{95 \%}$ & 0.88 & 0.88 & 0.00 \\
\hline $\mathrm{HI}$ & 0.22 & 0.24 & -0.02 \\
\hline \multicolumn{4}{|l|}{ Spinal cord } \\
\hline $\mathrm{D}_{\text {max }}(\mathrm{Gy})$ & 7.8 & 8.0 & -0.2 \\
\hline \multicolumn{4}{|l|}{ Oesophagus } \\
\hline $\mathrm{D}_{\max }(\mathrm{Gy})$ & 23.6 & 24.2 & -0.4 \\
\hline \multicolumn{4}{|l|}{ Stomach } \\
\hline $\mathrm{D}_{\max }(\mathrm{Gy})$ & 15.7 & 16.4 & -0.7 \\
\hline \multicolumn{4}{|l|}{ Duodenum } \\
\hline $\mathrm{D}_{\max }(\mathrm{Gy})$ & 10.2 & 10.8 & -0.6 \\
\hline \multicolumn{4}{|l|}{ Liver - GTV } \\
\hline $\mathrm{V}_{5}(\%)$ & 32 & 32 & 0 \\
\hline $\mathrm{V}_{10}(\%)$ & 20 & 21 & -1 \\
\hline $\mathrm{V}_{15}(\%)$ & 11 & 13 & -2 \\
\hline $\mathrm{V}_{20}(\%)$ & 6 & 6 & 0 \\
\hline $\mathrm{V}_{25}(\%)$ & 4 & 3 & 1 \\
\hline $\mathrm{V}_{30}(\%)$ & 2 & 2 & 0 \\
\hline $\mathrm{V}_{35}(\%)$ & 2 & 2 & 0 \\
\hline $\mathrm{V}_{40}(\%)$ & 1 & 1 & 0 \\
\hline $\mathrm{V}_{45}(\%)$ & 0 & 0 & 0 \\
\hline Mean dose (Gy) & 5.4 & 5.4 & 0.0 \\
\hline \multicolumn{4}{|l|}{ DFH parameter } \\
\hline \multicolumn{4}{|l|}{ Liver } \\
\hline $\mathrm{F}_{5}(\%)$ & 32 & 32 & 0 \\
\hline $\mathrm{F}_{10}(\%)$ & 18 & 21 & -3 \\
\hline $\mathrm{F}_{15}(\%)$ & 7 & 12 & -5 \\
\hline $\mathrm{F}_{20}(\%)$ & 4 & 4 & 0 \\
\hline $\mathrm{F}_{25}(\%)$ & 1 & 1 & 0 \\
\hline $\mathrm{F}_{30}(\%)$ & 1 & 1 & 0 \\
\hline $\mathrm{F}_{35}(\%)$ & 0 & 0 & 0 \\
\hline $\mathrm{F}_{40}(\%)$ & 0 & 0 & 0 \\
\hline $\mathrm{F}_{45}(\%)$ & 0 & 0 & 0 \\
\hline
\end{tabular}

DVH: Dose-volume histogram; PTV: planning target volume; CI: conformity index $\left[\mathrm{CI}=\mathrm{V}_{\text {Tref }} / \mathrm{V}_{\mathrm{T}} \times \mathrm{V}_{\text {Tref }} / \mathrm{V}_{\text {ref }}\right.$, where $\mathrm{V}_{\text {Tref }}$ is the volume of the target covered by the reference isodose, $\mathrm{V}_{\mathrm{T}}$ is the target volume and $\mathrm{V}_{\text {ref }}$ is the volume of the reference isodose (10)]; HI: homogeneity index $\left[\mathrm{HI}=\left(\mathrm{D}_{2 \%}-\mathrm{D}_{98 \%}\right) / \mathrm{D}_{50 \%}\right.$, where $\mathrm{D}_{\mathrm{x} \%}$ is the absorbed dose received by $\mathrm{x} \%$ of the planning target volume (10)].

\section{Authors' Contributions}

YK and RT conceived and designed the study, analysed and interpreted data and wrote the manuscript. TS, TM, YF, SS, YS and NO designed the study, interpreted data and reviewed the article. All Authors have read and approved the final manuscript.

\section{References}

1 Sherman M: Recurrence of hepatocellular carcinoma. N Engl J Med 359(19): 2045-2047, 2008. PMID: 18923166. DOI: 10.1056/NEJMe0807581
2 Peng Z, Chen S, Wei M, Lin M, Jiang C, Mei J, Li B, Wang Y, Li J, Xie X, Chen M, Qian G and Kuang M: Advanced recurrent hepatocellular carcinoma: Treatment with sorafenib alone or in combination with transarterial chemoembolization and radiofrequency ablation. Radiology 287(2): 705-714, 2018. PMID: 29390197. DOI: 10.1148/radiol.2018171541

3 Nishikawa H, Osaki Y, Iguchi E, Takeda H, Ohara Y, Sakamoto A, Hatamaru K, Saito S, Nasu A, Kita R and Kimura T: Percutaneous radiofrequency ablation therapy for recurrent hepatocellular carcinoma. Anticancer Res 32(11): 5059-5065, 2012. PMID: 23155279.

4 Kuang X, Ye J, Xie Z, Bai T, Chen J, Gong W, Qi L, Zhong J, Ma L, Peng N, Xiang B, Wu F, Wu G, Ye H, Wang C and Li L: Adjuvant transarterial chemoembolization to improve the prognosis of hepatocellular carcinoma following curative resection. Oncol Lett 16(4): 4937-4944, 2018. PMID: 30214612. DOI: $10.3892 / \mathrm{ol} .2018 .9244$

5 McDuff SGR, Remillard KA, Zheng H, Raldow AC, Wo JY, Eyler CE, Drapek LC, Goyal L, Blaszkowsky LS, Clark JW, Allen JN, Parikh AR, Ryan DP, Ferrone CR, Tanabe KK, Wolfgang JA, Zhu AX and Hong TS: Liver reirradiation for patients with hepatocellular carcinoma and liver metastasis. Pract Radiat Oncol 8(6): 414-421, 2018. PMID: 29937235. DOI: 10.1016/j.prro.2018.04.012

6 Toya R, Murakami R, Baba Y, Nishimura R, Morishita S, Ikeda O, Kawanaka K, Beppu T, Sugiyama S, Sakamoto T, Yamashita $\mathrm{Y}$ and Oya N: Conformal radiation therapy for portal vein tumor thrombosis of hepatocellular carcinoma. Radiother Oncol 84(3): 266-271, 2007. PMID: 17716760. DOI: 10.1016/j.radonc. 2007.07.005

7 Toya R, Saito T, Shiraishi S, Kai Y, Murakami R, Matsuyama T, Watakabe T, Sakamoto F, Tsuda N, Shimohigashi Y, Yamashita $\mathrm{Y}$ and Oya N: Dose-function histogram evaluation using ${ }^{99 \mathrm{~m} T c-}$ GSA SPECT/CT images for stereotactic body radiation therapy planning for hepatocellular carcinoma patients: A dosimetric parameter comparison. Anticancer Res 38(3): 1511-1516, 2018. PMID: 29491079. DOI: 10.21873/anticanres.12378

8 Bae SH, Jang WI and Park HC: Intensity-modulated radiotherapy for hepatocellular carcinoma: Dosimetric and clinical results. Oncotarget 8(35): 59965-59976, 2017. PMID: 28938697. DOI: 10.18632/oncotarget.19219

9 Beppu T, Hayashi H, Okabe H, Masuda T, Mima K, Otao R, Chikamoto A, Doi K, Ishiko T, Takamori H, Yoshida M, Shiraishi $\mathrm{S}$, Yamashita Y and Baba H: Liver functional volumetry for portal vein embolization using a newly developed $99 \mathrm{mTc}$-galactosyl human serum albumin scintigraphy spect-computed tomography fusion system. J Gastroenterol 46(7): 938-943, 2011. PMID: 21523415. DOI: $10.1007 / \mathrm{s} 00535-011-0406-\mathrm{x}$

10 Toya R, Saito T, Kai Y, Shiraishi S, Matsuyama T, Watakabe T, Sakamoto F, Tsuda N, Shimohigashi Y, Yamashita Y and Oya N: Impact of $99 \mathrm{~m}$ Tc-GSA SPECT image-guided inverse planning on dose-function histogram parameters for stereotactic body radiation therapy planning for patients with hepatocellular carcinoma: A dosimetric comparison study. Dose Response 17(1): 1559325819832149, 2019. PMID: 30858770. DOI: $10.1177 / 1559325819832149$

11 Shimohigashi Y, Toya R, Saito T, Ikeda O, Maruyama M, Yonemura K, Nakaguchi Y, Kai Y, Yamashita Y, Oya N and Araki $\mathrm{F}$ : Tumor motion changes in stereotactic body radiotherapy for liver tumors: An evaluation based on four-dimensional cone-beam 
computed tomography and fiducial markers. Radiat Oncol 12(1): 61, 2017. PMID: 28335794. DOI: 10.1186/s13014-017-0799-7

12 Yamamoto T, Kabus S, Bal M, Keall P, Benedict S and Daly M: The first patient treatment of computed tomography ventilation functional image-guided radiotherapy for lung cancer. Radiother Oncol 118(2): 227-231, 2016. PMID: 26687903. DOI: 10.1016/ j.radonc.2015.11.006

13 Thomas HMT, Zeng J, Lee HJ, Jr., Sasidharan BK, Kinahan PE, Miyaoka RS, Vesselle HJ, Rengan $\mathrm{R}$ and Bowen SR: Comparison of regional lung perfusion response on longitudinal MAA SPECT/CT in lung cancer patients treated with and without functional tissue-avoidance radiation therapy. $\mathrm{Br} \mathrm{J}$ Radiol 92(1103): 20190174, 2019. PMID: 31364397. DOI: 10.1259/bjr.20190174

14 Koay EJ, Owen D and Das P: Radiation-induced liver disease and modern radiotherapy. Semin Radiat Oncol 28(4): 321-331, 2018. PMID: 30309642. DOI: 10.1016/j.semradonc.2018.06.007

15 Kirichenko A, Gayou O, Parda D, Kudithipudi V, Tom K, Khan A, Abrams P, Szramowski M, Oliva J, Monga D, Raj M and Thai N: Stereotactic body radiotherapy (SBRT) with or without surgery for primary and metastatic liver tumors. HPB (Oxford) 18(1): 88-97, 2016. PMID: 26776856. DOI: 10.1016/j.hpb. 2015.07.007
16 Lee SW, Lee J, Lee DY, Chun KA, Ahn BC, Kang YM and Lee $\mathrm{K}$ : Evaluation of hepatic function with ${ }^{99 \mathrm{~m} T c \text {-galactosylated }}$ serum albumin scintigraphy in patients with malaria: Comparison with $99 \mathrm{mTc}$-colloid scintigraphy and liver ultrasonography. Nucl Med Commun 28(2): 95-99, 2007. PMID: 17198349. DOI: 10.1097/MNM.0b013e328013eae3

17 Huang Y, Chen SW, Fan CC, Ting LL, Kuo CC and Chiou JF: Clinical parameters for predicting radiation-induced liver disease after intrahepatic reirradiation for hepatocellular carcinoma. Radiat Oncol 11(1): 89, 2016. PMID: 27369241. DOI: 10.1186/ s13014-016-0663-1
Received September 7, 2020

Revised September 24, 2020

Accepted September 25, 2020 